\title{
Spor Yapan ve Spor yapmayan Lise Öğrencilerinin Özsaygı Düzeylerinin İncelenmesi
}

\section{Cihan BİNGÖL ${ }^{*}$ \\ Ufuk ALPKAYA}

\section{Öz}

Bu çalışmanın amacı, lise düzeyindeki spor yapan ve spor yapmayan öğrencilerin özsaygı düzeylerinin karşılaştırılmasıdır. Araştırmaya 2015-2016 eğitim-öğretim yılında Kağıthane ilçesinde okuyan, yaşları 15 - 18 (16.26 yaş \pm 1.02$)$ arasında olan toplam 320 öğrenci katılmıştır. Öğrenciler spor yapan ve spor yapmayan olarak 2 gruba ayrıca her grup da kadın ve erkek olarak 2 gruba ayrılmıştır.

Öğrencilerin öz saygı düzeylerini belirlemek için Coopersmith tarafından geliştirilen özsaygı ölçeği kullanılmıştır. İstatistiksel analizlerde, bağımsız t test yöntemi ile karşılaştırma yapılarak anlamlılık düzeyi $\mathrm{p}<0.05$ olarak belirlenmiştir.

Sonuçlara göre spor yapan öğrencilerin, spor yapmayan öğrencilerden daha yüksek özsaygı düzeyine sahip oldukları bulunmuştur $(\mathrm{p}<0.05)$. Ayrıca cinsiyete göre karşıllaştırıldığında, spor yapan erkek öğrencilerin, spor yapmayan erkek öğrencilerden ve spor yapan kız öğrencilerin de, spor yapmayan kız öğrencilerden daha yüksek özsaygı düzeyine sahip oldukları bulunmuştur $(\mathrm{p}<0,05)$.

Anahtar kelimeler: Özsaygı, lise, spor

* Lisans, Marmara Üniversitesi Spor Bilimleri Fakültesi, cihan.bingol@hotmail.com

** Doç. Dr., Marmara Üniversitesi Spor Bilimleri Fakültesi, ualpkaya@marmara.edu.tr 


\title{
The Investigation of the Self - Esteem Level of the Athletes and non-Athletes in High School Students
}

\begin{abstract}
The purpose of this study was to compaire the self - esteem between athletes and non-athletes in high school. Total number of 320 students (age: 15-20 year, mean:16.26 yaş \pm 1.02 ) were participated in this study in the 2015 - 2016 school year. The students divided in to non-athletes and athletes in gender too.

Self - Esteem questionnaire which was developed by Coopersmith was used to determine self - esteem level of the students. For he statistical analysis; independent $t$ tests was used to assess the differences in the self esteem among the groups. The significance level was set at $\mathrm{p}<0.05$.

According to results, it was found that the athletes have had higher self esteem scores than non-athletes $(\mathrm{p}<0.05)$. However comparing in gender, it was found that the male athletes have had higher selfesteem srores than male non-athletes and female athletes have had higher self-esteem scores than female non-athletes $(\mathrm{p}<0.05)$.
\end{abstract}

Keywords: Self - esteem, high school, athletes

\section{GiRiş}

Özsaygı, bireyin özünü bir nesne olarak ele alıp onu değerlendirmesi sonucunda kendisi hakkında vardığı yargı ve geliştirdiği tutumdur. Farklı ifadelerle benlik saygısı, öze saygı, kendine saygı gibi terimlerle ifade edilmektedir. (Kuzgun 2000, Coopersmith 1974, Yiğit, Yllmaz 2011).

Coopersmith (1974) özsaygıyı, bireyin kendini yetenekli, önemli, başarılı ve değerli olarak algılama derecesi olarak belirtmektedir. Ayrıca, kişinin kendisine ilişkin yaptığı ve alışkanlık haline getirdiği değerlendirmenin, özsaygıyı oluşturduğu ve bunun kendi değerliliğine ilişkin bir yargı olduğunu da vurgulamaktadır.

Yiğit ve Yılmaz (2011) öz saygıyı, kişiliğin önemli bir boyutu ve olumlu bir kişilik özelliği olduğunu ve bireyin toplum içinde davranışlarını etkileyen olgu karşısında vereceği tepkileri belirleyen kendisini değerli, önemli, başarılı, yetenekli olumlu, beğenilmeye ve sevilmeye değer olduğunu hisseden, özüne güvenmeyi sağlayan olumlu bir ruh hali olarak tanımlamıştır.

Maslow (1942), bireyin gerçek anlamda verimli ve başarılı olması için, sağlıklı bir benlik saygısına sahip olması gerektiğini savunur. Maslow’a göre, benlik saygısının iki kaynağı vardır: Birincisi, bireyin önem verdiği kişilerden gördüğü sevgi, saygı ve kabul; ikincisi ise bireyin yetkinlik ve başarı duygularıdır. Coopersmith (1974) ise gerçek özsaygı ve savunucu özsaygı olarak iki tip saygı görünümü olduğunu ve gerçek özsaygının, kendilerini gerçekten saygın ve değerli hissedenlerde, savunucu özsaygının ise kendilerini değersiz hisseden ancak böyle bir yargıyı kabullenemeyen kişilerde bulunduğunu savunmaktadır. 
Bireylerin yaşamının farklı yönlerini etkileyen bir kişilik değişkeni ve sağlıklı bir kişiliğin gelişiminin ön koşulu özsaygıdır (Güloğlu ve Aydın2001). Öz saygı, kişiliğin önemli bir parçası olarak, bireyin hayatının tüm yönlerini etkileyerek onun davranışlarına yön verebilmektedir. Kişilik gelişiminde önemli bir yer tutan ve birey için önemli olan alg1, duygu ve düşüncelerin bir bütünü olan benlik saygısı, bireyin sosyalleşme düzeyinde önemli bir rol oynamaktadır (Deniz ve ark. 2008).

Günlük yaşamda dışarıdan özsaygıya yönelik tehditler, bireylerin özsaygılarını etkiler. Özsaygısı düşük kişiler, özsaygısı yüksek olanlara göre daha çok tehditlere açıktır. Öz saygıları yüksek kişiler ise, olumsuz eleştirileri dikkate almazlar ve bu eleştirilerin kendilerini doğru bir şekilde tarif etmediğini düşünürler. Benlik kavramlarından emin olmayan düşük özsaygıya sahip kişiler ise bu eleştirilerin doğru olabileceğini düşünürler. Bu yüzden eğer birey iyi özelliklerinden emin değilse, özsaygısı tehdit edilmeye açık hale gelir (Baumeister 1993). Ayrıca, öz saygısı yetersiz olan bireyler, kendilerini değersiz ve yetersiz gören, olaylarla başa çıkma güçlerinin olmadığını düşünen, çevreden çabuk etkilenen, inanç ve tutumlarını kolaylıkla değiştiren düşük benlik saygısına sahiptirler. Bu bireyler günlük yaşamda karşılaştıkları streslerle başa çıkmada güçlük çekerler ve bu duygularını kontrol etmekten uzaktırlar. Benlik saygısı düzeyi yüksek olan bireyler ise gerek sosyal ilişkilerinde gerekse okul çalışmalarında daha girişimci, daha güvenli ve daha ataktırlar. Yeni şeyler öğrenmeye daha meraklıdırlar ve yeni durumlarla karşılaşmaktan kaçınmazlar. Öz saygısı düzeyleri düşük kişiler ise bunların aksine, kendilerine daha az güven duyar ve onlardan istenenleri başaramayacakları duygusunu daha yoğun yaşarlar. Bu nedenledir

ki, başarısızlık sonrası oluşacak doğal mahcubiyet duygusunu yaşamamak için bu gibi riskli durumlardan kendilerini sürekli olarak uzak tutmaya çalışırlar (Pişkin 2003).

Öz saygıyı arttırma çabası, bireyin kendisini yetkin, değerli ve başkaları tarafından sevilen biri olmayı hissetme ihtiyacından doğar. Birey, çevresi tarafından kişisel değer duygularını artıran onay aldığı zaman memnun olur ve olumlu tepkide bulunur. Kendi değerlerinin başkaları tarafından onaylanmadığı zaman engellenir, hayal kırıklığı yaşar (Whitehead ve Corbin, 1997).

Yüksek benlik saygısı olan birey, başarılarını büyük ölçüde kendi emeği ve becerisi olarak görür. Kendi kontrol duygusunu hisseder ve başarısızlığa uğradığında daha iyisini yapmak için motive olur. Değişiklikler yapmaya ve daha fazla çalışmaya ihtiyaç duyduğunun farkına vararak, hatalarını kabul eder ve başkalarını suçlamaktan kaçınır (Yavuzer, 2003; Baumeister 1993).

Spor ve fiziksel aktivitelerle uğraşan kişilerde stres, kaygı ve depresyon düzeyi, öz saygı durumunu inceleyen çalışmalarda genel olarak olumlu sonuçlara rastlanmıştır. (Pınar 2002; Karakaya ve ark., 2006; Garry ve Morrissey 2000 ).

Çalışmamızda, bu bilgiler ışığında düzenli spor yapan ve spor yapmayan sedanter kişilerde öz saygı durumunu tespit etmek amaçlanmıştır.

\section{YÖNTEM}

Bu çalışmada örneklem tarama modeli seçilerek İstanbul ilinde Kağıthane ilçesinde belirlenen çok Programlı Lisesi ve İHKİB Kağıthane Mesleki ve Teknik Anadolu Lisesi oluşturmaktadır. 
Araştırma kapsamında yaşları 15 - 18 (16.26 yaş \pm 1.02$)$ arasında düzenli spor yapan 160 kişi ve spor yapmayan 160 kişi toplam 320 kişi katılmıştır. Araştırmaya 114 kız öğrenci, 206 erkek ögrrenci katılmıştır. Araştırmaya katılan kızların 42'si spor yapan 72'si ise spor yapmayan öğrencilerden, araştırmaya katılan erkeklerin ise 118'i spor yapan 88'i ise spor yapmayan öğrencilerden oluşmuştur. Düzenli spor yapan grubun haftada en az $3 \mathrm{kez}$ antrenman yaptıkları ve hepsinin lisanslı kulüp sporcusu olmalarına dikkat edilmiştir.

Araştırmada, Coopersmith tarafından geliştirilen ve Pişkin (1996) tarafından güvenirlik kapsamı (0.70) belirlenen özsaygı ölçeği (25 soru) kullanılmıştır. Bu amaçla Kağıthane Çok Programlı Lisesi ve İHKİB Kağıthane Mesleki ve Teknik Anadolu Lisesi’ndeki okul müdürleri ile görüşülüp ölçek uygulama izni alınmış ve okul beden eğitimi dersi öğretmenleri yardımı ile ölçekler uygulanmıştır. Ölçekler öğrencilere dağıtıldıktan sonra nasıl yanıtlanacağı anlatılmış, 10 dakika süre verilmiş, ölçeklerin cevaplanma süresince her türlü soru ve problemde öğrencilerin ölçekleri uygun şekilde cevaplamaları sağlanmıştır.

Ölçekteki soruların hepsi bilgisayar spss programına yüklenmiş ve tüm veriler spor yapan ve spor yapmayan olarak karşılaştırılmıştır. Bağımsız t test yöntemi ile karşılaştırma yapılarak anlamlılık düzeyi $\mathrm{p}<0.05$ olarak belirlenmiştir.

\section{BULGULAR}

Tablo I. Tüm Öğrencilerin Spor Yapma ve Spor Yapmama Durumuna Göre Özsaygı Düzeylerinin Karşılaştırılması

\begin{tabular}{lccccc}
\hline Değişken & n & x & ss & t & p \\
\hline Spor Yapan & 160 & 19,94 & 2,442 & & \\
Spor Yapmayan & 160 & 17,97 & 3,966 & 5,364 &, 000 \\
\hline
\end{tabular}

Sonuçlara göre spor yapan öğrencilerin, spor yapmayan öğrencilere göre özsaygı düzeylerinde $(\mathrm{p}<0.05)$ istatistiksel olarak anlamlı fark bulunmuştur.

Tablo 2. Erkek Öğrencilerin Spor Yapma ve Spor Yapmama Durumuna Göre Özsaygı Düzeylerinin Karşılaştırılması

\begin{tabular}{lccccc}
\hline Değişken & $\mathbf{n}$ & $\mathbf{x}$ & ss & t & p \\
\hline Spor Yapan & 118 & 19,96 & 2,405 & & \\
Spor Yapmayan & 88 & 18,33 & 3,577 & 3,902 &, 000 \\
\hline
\end{tabular}

Sonuçlara göre spor yapan erkek öğrencilerin, spor yapmayan erkek öğrencilere göre özsayg1 düzeylerinde $(\mathrm{p}<0,05)$ istatistiksel olarak anlamlı fark bulunmuştur. 
Tablo 3. Kız Öğrencilerin Spor Yapma ve Spor Yapmama Durumuna Göre Özsaygı Düzeylerinin Karşılaştırılması

\begin{tabular}{lccccc}
\hline Değișken & $\mathbf{n}$ & $\mathbf{x}$ & ss & $\mathbf{t}$ & $\mathbf{p}$ \\
\hline Spor Yapan & 42 & 19,90 & 2,57 & 3,206 & 0,002 \\
Spor Yapmayan & 72 & 17,53 & 4,38 & & \\
\hline
\end{tabular}

Sonuçlara göre spor yapan kız öğrencilerin, spor yapmayan kız öğrencilere göre özsaygı düzeylerinde $(\mathrm{p}<0,05)$ istatistiksel olarak anlamlı fark olduğu sonucuna varılmıştır.

\section{TARTIŞMA}

$\mathrm{Bu}$ çalışmanın amacı düzenli spor yapan ve spor yapmayan lise öğrencilerinin özsaygı düzeyleri arasında fark olup olmadığı araştırılmıştır.

Sonuçlara göre spor yapan tüm öğrencilerin, spor yapmayan tüm öğrencilere göre özsayg1 düzeylerinde $(\mathrm{p}<0.05)$ istatistiksel olarak anlamlı fark olduğu bulunmuştur. Ayrıca cinsiyete göre karşılaştırıldığında, spor yapan erkek öğrencilerin, spor yapmayan erkek öğrencilere göre ve spor yapan kız öğrencilerin, spor yapmayan kız öğrencilere göre özsaygı düzeylerinde istatistiksel olarak anlamlı fark olduğu bulunmuştur $(\mathrm{p}<0,05)$

Literatürde yapılan araştırmalarda ulaşılan sonuçlar bizim yapmış olduğumuz araştırmayla paralellik gösterip, yapmış olduğumuz araştırmayı destekler niteliktedir. Nitekim yapılan araştırmalarda spor yapan bireylerin sahip olduğu özsaygı düzeyleri spor yapmayan bireylerin sahip olduğu özsaygı düzeylerinden daha yüksek bulunmuştur.

Sporun özsaygıya olan etkisini araştırmaya yönelik yapılan çalışmalarda; Tozoğlu ve Ark. (2014) tarafından yapılan araştırma sonucunda spor yapan engelli bireylerin özsaygısının spor yapmayan engelli bireylerden yüksek olduğu ve haftalık spor yapma süresi arttıkça da özsaygı seviyesi de aynı paralellikte arttığı gözlemlenmiştir. Sporun sadece sağlık düzeyi iyi olan bireylerde değil

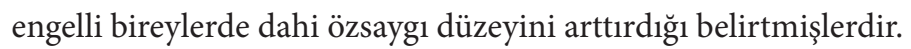

Gacar ve Yanlıç (2012)'ın yapmış olduğu araştırmada hentbol oynayan ve spor yapmayan 1317 yaş arasındaki çocukları karşılaştırmasında, Karakaya ve ark. (2006) yüzücülerle spor yapmayanları karşılaştırmasında ayrıca Smith'in 1979'da yapmış olduğu araştırmada beyzbol oynayan çocukların spor yapmayanlarla karşılaştırılmalarında, sportif etkinlik yapan grupların diğerlerine göre daha yüksek özsaygı seviyesine sahip olduklarını bulmuşlardır.

Salokun (1990) ve Vincent (1976)'in yapmış oldukları araştırmalarda da spor yapan bireylerin,spor yapmayan bireylerden daha yüksek benlik kavramına sahip oldukları belirlenmiştir. 


\section{SONUÇ}

Yukarıda yapılan araştırmalardan görüleceği üzere sporun özsaygı üzerindeki etkisi pozitif yönde olup sporun özsaygı düzeyini arttırdığı görülmektedir.

$\mathrm{Bu}$ sonuçlar göz önünde bulundurulduğunda; Düzenli spor yapmanın insan hayatındaki etkisi ve öneminin büyük olduğu anlaşılmaktadır. Spor bireylerde özsaygı düzeyini arttırması onların kendileriyle daha barışık bir şekilde yaşamalarını ve hayata daha olumlu bakmalarını sağlamaktadır. 


\section{KAYNAKLAR}

Baumeister, R. F. (1993). Inner Nature of Low Self-Esteem. R.F. Baumeister (ed.). Self-Esteem: The Puzzle of Low Self-Regard. 186-225. New York: Plenum

Coopersmith, S. (1974). The antecedents of self-esteem. W.H. Freeman. and Company, San Francisco.

Deniz, M.E., Traş, Z. ve İlaslan, Ö. (2008). Self esteem and decısıon makıng: a research on unıversıty students. 11th International Conference On Further Education In The Balkan Countries

Gacar, A., Yanlıç N. (2012). 13 - 17 yaş ergen hentbolcuların benlik saygısı düzeylerinin bazı değişkenler açısından incelenmesi. Spor ve Performans Araştırmaları Dergisi Journal of Sports and Performance Researches. Cilt / Vol : 3 Say1 / No : 2 Yll

Garry, JP. Ve Morrissey, SL. (2000). Team Sports Participation and Risk-taking Behaviours Among a Biracial Middle School Population. Clin. J. Sport Med, 10,185-190.

Güloğlu, B. ve Aydın, G. (2001). Coopersmith özsaygL envanteri’nin faktör yapısı. Eğitim ve Bilim, 26 (122), 66-71.

Karakaya, I., Coşkun, A., Ağaoğlu, B. (2006). "Yüzücülerin Depresyon, Benlik Saygısı ve Kaygı Düzeylerinin Değerlendirilmesi” Anadolu Psikiyatri Dergisi, 7, 162-166.

Kuzgun, Y. (2000). Meslek Danışmanlığı. Ankara: Nobel Yayın Dağıtım.

Maslow A,H. (1942) Selfesteem (dominance - feeling ) and sexuality in woman. The journal of Social Psychology.

Pınar, R. (2002). Obezlerde Depresyon, Benlik Saygısı ve Beden Đmajı: Karşılaştırmalı Bir Çalışma. C.Ü. H.Y.O. Dergisi, 6 (1), 30-41.

Pişkin, M. (2003). Özsaygı geliştirme eğitimi. (ed. Y. Kuzgun) İlköğretimde Rehberlik. Ankara: Nobel Yayınlar1, 95-123.

Salokun, S.D. (1990). "Comparision of Nigerian High SchoolAthletes and Nonathletes On Self-concept". Perceptual and Motor Skills. 70. 865-866.

Tozoğlu, E; Bayraktar, G; Aka, S T.; Tatlısu, B. ( 2014) Studyıng the Effects of Sportıng Habits on the Selfesteem of Disabled Indİviduals. Journal of Physical Education \& Sports Science / Beden Egitimi ve Spor Bilimleri Dergisi . Vol. 8 Issue 2, p233-241. 9p.

Yavuzer, H. (2003). Çocuğu tanımak ve anlamak. İstanbul: Remzi Kitabevi.

Vincent, M.F. (1976) "Comparision of Self-concept of College Woman: Athletes and Physical Education Majors". Research Quarterly. 47, 218-225.

Whitehead, J. R. ve Corbin, C. B. (1997). Self Esteem in Children and Youth: The Role of Sport and Physical Education. Fox, K. R. (ed.). The Physical Self: From Motivation to Well-Being. 175-203. New York: Broun Brumfield

Yiğit, R.ve Yılmaz, H. (2011). İlköğretim II. Kademe Öğrencilerinin Sosyal Beceri Düzeyleri ile Benlik Saygısı Arasındaki İlişkinin İncelenmesi. Selçuk Üniversitesi Ahmet Keleşoğlu Eğitim Fakültesi Dergisi,31,335- 347 
